\title{
Decompressive Craniectomy in Pediatric Severe Head Trauma
}

\section{Angel J Lacerda Gallardo ${ }^{*}$, Daysi Abreu Pérez², Miguel Mazorra Pazos ${ }^{1}$, Gustavo P Valdivieso Caraguay $^{1}$, Gustavo M Obregón Criales ${ }^{2}$ and Paschal Edes Songoro ${ }^{3}$}

${ }^{1}$ Department of Neurosurgery, Roberto Rodriguez General Hospital, Cuba

${ }^{2}$ Pediatric Intensive Care Unit, Roberto Rodriguez General Hospital, Cuba

${ }^{3}$ Mbeya Zonal Referral Hospital, Tanzania

*Corresponding author: Angel J Lacerda Gallardo, MD, PhD, Department of Neurosurgery, Roberto Rodriguez General Hospital, Moron, Ciego de Avila, Cuba, E-mail: ajlacerda@hgm.cav.sld.cu

\begin{abstract}
Objectives: To evaluate in a general way the usefulness of early decompressive craniectomy in pediatric patients with severe traumatic brain injury, the time elapsed from the moment of trauma to the arrival at the neurotrauma center, Glasgow coma scale on admission and its possible association with discharge results and evaluate the results of the computerized tomography images on admission and sequential, as well as the behavior of intracranial pressure and cerebral perfusion pressure.
\end{abstract}

Patients and methods: A descriptive study with 36 patients admitted in our pediatric intensive care unit from January 2003 to December 2016 was carried, in which an early decompressive craniectomy was performed to reduce the refractory intracranial hypertension from a severe head trauma.

Results: 22 patients were treated with primary decompressive craniotomy and 14 with delayed decompressive craniotomy. Initial computerized tomography showed grade IV diffuse axonal lesion in $50 \%$ of cases and intracranial pressure after decompressive craniotomy was below the normal values for each age group in $68.18 \%$. Glasgow outcome Scale at 1 year of evolution showed $59.09 \%$ with grade $V$ and a mortality of $22.73 \%$ (grade I).

Conclusion: In children who suffered severe head trauma with refractory intracranial hypertension, early decompressive craniectomy may be an effective method to treat the secondary deterioration that commonly leads to death or severe neurological deficit.

\section{Keywords}

Decompressive craniectomy, Surgical treatment, Severe traumatic brain injury

\section{Introduction}

Severe head trauma (SHT) is the leading cause of death in children older than one year of age in the first world. It is the cause of over 630,000 visits to emergency departments, 60,000 admissions and 6,000 deaths in children between 0-19 years of age in the United States of America each year [1].

When comparing the incidence of injuries between children and adults, it has been known that the former suffers from head trauma with a greater frequency [2], however, a considerable small number of studies aimed at evaluating the care or effects of different types of therapy has been carried out in the acute phase of trauma or rehabilitation in children as compared to adults [3-5].

The fundamental objective of the treatment for children with severe $\mathrm{TBI}$ is to correct the primary lesion generated in the traumatic event and to minimize the secondary lesion that appears as a consequence of complex biochemical mechanisms in damaged brain tissue [6-8].

For several decades it has been known that in many cases with severe TBI, the clinical picture is not a totally reliable indicator of the behavior of some intracranial parameters such as ICP, especially if the patient is under sedation or neuromuscular blockade with assisted mechanical ventilation. The evidence of $\mathrm{ICH}$ events without clinical changes in this kind of patients represents a serious risk factor for mortality and has motivated the

Citation: Gallardo AJL, Pérez DA, Pazos MM, Caraguay GPV, Criales GMO, et al. (2018) Decompressive Craniectomy in Pediatric Severe Head Trauma. Int J Pediatr Res 4:033. doi.org/10.23937/24695769/1510033

Accepted: June 09, 2018: Published: June 11, 2018

Copyright: (c) 2018 Gallardo AJL, et al. This is an open-access article distributed under the terms of the Creative Commons Attribution License, which permits unrestricted use, distribution, and reproduction in any medium, provided the original author and source are credited. 
almost generalized recommendation of monitoring as many intracranial parameters as possible to ensure a safe knowledge of intracranial physiology in these conditions and thus make it possible for the proper management, with appropriate measures, at the right time.

In this context DC is a surgical procedure that is used to control of $\mathrm{ICH}$ that is refractory to the best medical treatment, with which satisfactory results have been obtained both in adults as well as in the pediatric population. The adequate selection of the patients who undergo the procedure, as well as the moment at which it is indicated, seem to be the two fundamental questions related with the results [9-13].

It is a procedure that has been used in the management of brain tumors, encephalopathy of Reye syndrome, ischemic and hemorrhagic strokes, infectious processes of the central nervous system, as well as in severe $\mathrm{TBI}$ with uncontrollable $\mathrm{ICH}$. However, there is still no consensus on the ideal time to propose the procedure, nor what its real benefits are. The latest treatment guidelines for the pediatric patient recommend it as an option in patients with progressive deterioration of the level of consciousness, incipient signs of cerebral herniation or refractory $\mathrm{ICH}$ in the initial stages of treatment [14].

In the national context there are very few publications on the subject, mostly from the neurosurgical team at "Roberto Rodríguez" hospital, in the province of Ciego de Ávila, Cuba, where the present study was done, in which since the end of the 90 s of the last century, an intensive treatment protocol for the pediatric patient was initiated and executed simultaneously with that developed for adults, representing the largest experience in the country accumulated on the subject, which endorses the services of neurosurgery and pediatric intensive care as a reference center on the subject in the country.

The experience accumulated by the senior author and his team since 1996 with the use of DC for the control of $\mathrm{ICH}$ in pediatric patients and adults with severe $\mathrm{TBI}$ as well as ischemic and hemorrhagic strokes, constitutes the first approach to this topic in our country and led us to pose the following research problem: How to reduce ICP early in pediatric patients with severe TBI with associated $\mathrm{ICH}$, to reduce secondary brain damage and improve morbidity and mortality? The hypothesis that early use of DC can control ICP in pediatric patients with severe $\mathrm{TBI}$ and uncontrollable $\mathrm{ICH}$ and thus improve short-term results led us to consider the following research objectives: To evaluate in a general way the usefulness of early $D C$ in pediatric patients with severe $\mathrm{TBI}$, the time elapsed from the moment of trauma to the arrival at the neurotrauma center, the Glasgow coma scale (GCS) on admission and its possible association with the discharge results, and to evaluate the results of the CT images on admission and sequential, as well as the behavior of ICP and CPP.

\section{Patient and Methods}

A longitudinal prospective descriptive study of correlation type was carried out with all the patients admitted to the pediatric intensive care unit, with the diagnosis of severe TBI, in the period between January 2003 and December 2016.

The universe was represented by 36 patients from 1 month of age up to 18 years, attended in the pediatric intensive care unit of our hospital; the sample corresponds to the universe.

The information was obtained at the time of admission and during the hospital stay, which was poured into a data collection notebook prepared for the study, which considered variables such as age, sex, personal and family medical history, neurosurgical history, origin and month in which the accident or trauma occurred, as well as the day of the week.

Variables related to the traumatic event were also contemplated, such as: Clinical status at the moment of admission evaluated by the GCS [15], time elapsed from the moment of trauma to moment of initial care at the neurotrauma center, health transportation used, prehospitalization therapeutic measures, characteristics of CT scan images on admission and sequential imaging results, behavior of the ICP, CPP, results of the calculation of the pressure-volume relation and complications.

\section{Age}

The patients were divided into three subgroups according to their age and normal values of ICP: Infants from 30 days of age to 11 months and 29 days, pre-scholars from one to four years, school children from five to 18 years.

\section{Glasgow Coma Scale (GCS) on admission}

The GCS on admission was divided into three subgroups to relate it to other variables. Subgroup I included patients with eight points, subgroup II scored between seven and six points and subgroup III patients scored between five and four points.

\section{Indications and analysis of CT scan images}

CT scan studies were performed on admission and after every 72 hours. Urgent CT scan was also indicated for any deterioration of the neurological status or sustained elevations of the ICP above the normal values for each age group for 15 minutes. The evaluation of the emergency CT scan images was done by the neurosurgeon on duty and the subsequent imaging results were discussed by a group of specialists constituted by neurosurgeons, radiologist and pediatric intensivists, with the aim of obtaining a collegiate diagnosis and consequently adopt the treatment. 
The CT scan images on admission were evaluated according to the classification of Marshall, et al. [16].

The volume of the focal lesions was calculated according to the ellipsoid method $(A \times B \times C / 2)$, where $A=$ greater length, $B=$ greater width and $C=$ height.

The shift of the midline was calculated in millimeters and divided into subgroups: a) Between one and five, b) Between six and 10, c) Greater than 10.

For the better analysis, subsequent CT images were divided into three subgroups qualitatively and the categories were considered as follows: a) Improved, b) Equal, c) Worse.

\section{Continuous ICP monitoring}

Continuous ICP monitoring was done by placing a catheter in the lateral ventricle of the most affected side, determined clinically or using imaging results. When it was not possible to perform the ventriculostomy, the catheter was placed in the subarachnoid or intraparenchymal space and in all cases, it was externalized by epicranial subcutaneous tunneling, three centimeters distant from the surgical wound to reduce the risk of infection.

The catheter was connected to a monitoring device with an external pressure transducer (Integra Neuroscience) that, after having been properly calibrated, transforms the liquid wave (pressure wave) into an electrical signal that is amplified and displayed on the screen of a monitor (Life Scope of the Nihon Koden or Doctus VII of national manufacture), through the use of the invasive monitoring circuit of the MAP or the low pressure channel, with which it is possible to obtain its graphic registration.

Patients were divided according to the ICP values for each age group. Infants: Normal values 2-6 mmHg, were divided into a) Less than $6 \mathrm{mmHg}$, b) Greater than $6 \mathrm{mmHg}$. Children older than 1 year: Normal values between $3-15 \mathrm{mmHg}$, as the range of pressures is as wide as the age range, this group is divided into two subgroups (considering the existence of buffer mechanisms up to four years approximately) in children aged 1-4 years in a) Less than $10 \mathrm{mmHg}$ and b) Greater than 10 $\mathrm{mmHg}$. For the children between 5-18 years in a) Less than $15 \mathrm{mmHg}$ and b) Greater than $15 \mathrm{mmHg}$.

$\mathrm{ICH}$ was treated when the values were higher than the normal value for each age group, with the exception of those that presented intracranial space-occupying lesions, located in the uncus of the temporal lobe or in the basal frontal region, in which therapeutic behaviors were evaluated personally.

\section{Methods Used to Control ICP}

Those who showed normal values for their age for 24 hours, the catheter was removed, and they continued with general support measures until their recovery.
If the ICP values were above the normal value for their age for 15 minutes, pain relief with metamizol was given intravenously at a dose of $25 \mathrm{mg} / \mathrm{Kg} / \mathrm{doses} / 4-6 \mathrm{~h}$. Sedation was performed predominantly with short halflife benzodiazepines, such as midazolam, at doses of $0.3-0.8 \mathrm{mg} / \mathrm{Kg} / \mathrm{h}$. In some cases, the combination of this drug with fentanyl was used at doses of 3-6 $\mu \mathrm{g} / \mathrm{Kg} / \mathrm{h}$ in continuous infusion, as pain relief and sedation. If control was not achieved with this measure, cerebrospinal fluid was drained through the ventriculostomy. Serial extractions were performed on no more than four occasions in one hour, with a maximum of five milliliters each time.

If ICP was not controlled, boluses of $20 \%$ mannitol were administered at a dose between $0.25 \mathrm{~g} / \mathrm{Kg} /$ dose (occasionally $1 \mathrm{~g} / \mathrm{kg} /$ dose), which were repeated four hourly and alternately or simultaneously moderate hyperventilation was used to reach values of arterial partial pressure of carbon dioxide $\left(\mathrm{PaCO}_{2}\right)$ between 30 and $35 \mathrm{mmHg}$.

If the high ICP levels were maintained, neuromuscular relaxation was done with pancuronium methyl bromide, using an attacking dose of $0.8-1 \mathrm{mg} / \mathrm{Kg} /$ dose, whenever necessary or vecuronium $0.1-0.2 \mathrm{mg} / \mathrm{kg} / \mathrm{dose}$ that causes less cardiovascular effects, to the cases that ICP was not controlled; second level treatment measures (starting with the DC) were applied.

The surgical procedures used were the bifrontal DC, which is limited forward by both orbital rims (floor of the frontal base), backwards by the coronal suture and laterally by both zygomatic arches. The uni or bilateral fronto-temporo-parietal DC, is another technique of $D C$, the diameter of this variant is limited in front by the frontal sinus, at the upper end it is located one-centimeter lateral to the sagittal midline, the lower end reaches the zygomatic arch (it includes all the temporal scale to the cranial base) and behind it extends to a vertical line located at approximately $2 \mathrm{~cm}$ behind the trailing edge of the auricle. In general, it was tried that the diameters of the craniectomy surpassed the limits of the lesion 2-3 $\mathrm{cm}$.

Patients with deteriorated clinical status (GCS: 4-5) and imaging evidence of $\mathrm{ICH}$ such as mass effect with median line shift greater than $5 \mathrm{~mm}$, narrowed ventricles with absence of subarachnoid space and compressed basal cisterns and mass lesions not evacuated were also operated on.

Those cases who once operated on, maintained high ICP values and persistent median line shift greater than 5 millimeters in the sequential CT scan were evaluated for the use of second-level tiers, such as optimized hyperventilation to achieve values of $\mathrm{PaCO}_{2}$ around 25 $\mathrm{mmHg}$, barbiturate coma or DC. In those who had already undergone this procedure, the diameter of DC was evaluated and if it was less than $12 \mathrm{~cm}$ (insufficient 
to provide the necessary space for cerebral re-accommodation), they underwent a reoperation to increase the decompression area. Those patients who showed worsening pre-existing focal lesions or those who presented new lesions were also re-operated on for their evacuation.

\section{Determination of CPP}

CPP was calculated according to the conventional formula CPP = MAP - ICP, where MAP is the mean arterial pressure obtained in turn by the formula $2 \mathrm{X}$ diastolic pressure plus the systolic pressure and the resulting answer divided by 3 and the ICP is the intracranial pressure at the moment of performing the calculation. As the MAP values vary according to the age groups and their normal range fluctuates between the third and $90^{\text {th }}$ percentile, also ICP values vary according to age, for the calculation of this variable we used the minimum values of MAP and maximum values of the ICP for each age group. Optimal values were considered to be: For infants, $51 \mathrm{mmHg}$. The results were divided into a) Less than $51 \mathrm{mmHg}$ and b) Greater than $51 \mathrm{mmHg}$. For children between 1-4 years old the normal value was 52 $\mathrm{mmHg}$, so they were divided into a) Less than $52 \mathrm{mmHg}$ and b) Greater than $52 \mathrm{mmHg}$ and for children between 5-18 years the normal figure is $60 \mathrm{mmHg}$, for which were also divided into a) Less than $60 \mathrm{mmHg}$ and b) Greater than $60 \mathrm{mmHg}$.

\section{Statistical Analysis}

In order to process the information, database was created in the SPSS system version 18 for Windows. The nonparametric test of goodness of fit of Chi squared was used to evaluate hypotheses about the relationship between two variables. Values of $p \leq 0.05$ were considered significant.

The results were evaluated at discharge according to the Glasgow Outcome Scale (GOS) [17], which classifies them as follows: grade I: deceased, grade II: persistent vegetative state, grade III: severe sequelae, grade IV: sequelae moderate, grade V: slight sequelae or no sequelae. Grades I, II and III were considered unsatisfactory results, while grades IV and V, were considered satisfactory.

\section{Results}

Of the 36 patients, 31 (86.11\%) were between five and 18-years-old, and another five (13.89\%) between one and four, with an average age of nine years. 31 patients $(86.11 \%)$ were male and five were female (13.89\%).

The GCS on admission was divided into three subgroups to relate it to other variables and we found that 16 cases $(44.44 \%)$ scored eight points, nine patients (25\%) scored between seven and six and 11 patients $(30.56 \%)$ scored between five and four points.
The analysis of the CT scan images at admission showed that 18 patients (50\%) had a diffuse axonal lesion (DAL) grade IV, 10 (27.78\%) showed a DAL grade III and eight (22.22\%) a lesion with mass effect non-evacuated (LMENE).

When evaluating the shift of the midline structures in the CT scan taken on admission, 17 (47.22\%) presented a midline shift greater than $10 \mathrm{~mm}, 11$ (30.56\%) between six and $10 \mathrm{~mm}$ and $8(22.22 \%)$ presented with a shift less than $5 \mathrm{~mm}$.

Twenty-two patients (61.11\%) underwent emergency DC without previous monitoring of ICP. In other eight patients $(22.22 \%)$, focal intracranial lesions were removed (acute subdural hematomas) through a craniotomy with dura closure without enlargement and duroplasty, the bone flap was replaced. In those 30 patients a catheter was placed in the lateral ventricle of the affected side and they were transferred to the pediatric intensive care unit for continuous ICP monitoring. In the other six patients (16.67\%), showing diffuse lesion grade I-II on CT scan, only the catheter was placed for ICP monitoring.

The last 14 cases (38.89\%) presented neurological deterioration in the following 12 hours of evolution and developed $\mathrm{ICH}$ refractory to medical treatment. When evaluating the sequential CT scan images of these 14 patients, all showed imaging deterioration (100\%), characterized by six $(42.86 \%)$ collections of juxtadural focal lesions, associated with cerebral edema and increase in the degree of midline shift, eight patients (57.14\%) with severe, diffuse, bilateral cerebral edema with cleft ventricles, absence of subarachnoid space and absence of basal cisterns. In one case $(7.14 \%)$ it was associated with severe diffuse intracranial hemorrhage, secondary to a coagulopathy, which required multiple therapeutic maneuvers for its stabilization. In all these 14 patients a delayed DC was done.

In six patients (16.67\%), bifrontal DC was performed (Figure 1) and in 30 (83.33\%) a fronto-temporo-parietal (FTP) DC.

The values of the continuous recording of the ICP in the 22 patients which the primary DC was performed were: Less than $20 \mathrm{mmHg}$ in 14 (63.64\%) ( $\mathrm{p} \leq 0.00$ ), between $21-25 \mathrm{mmHg}$ in six cases (27.27\%), and greater than or equal to $25 \mathrm{mmHg}$ in two patients (9.09\%).

The behavior of preoperative ICP in the 14 cases (38.89\%) who did not undergo primary DC showed higher values for their age. In six cases (42.86\%), values of 21-25 $\mathrm{mmHg}$ were presented, despite the application of medical treatment protocol for $\mathrm{ICH}$, the values were greater than $25 \mathrm{mmHg}$ in eight patients (57.14\%) (Figure 2). After a delayed DC was done, the ICP was controlled in 10 patients $(71.43 \%)(p \leq 0.00)$ and four cases (28.57\%) maintained ICH (Figure 2a). 


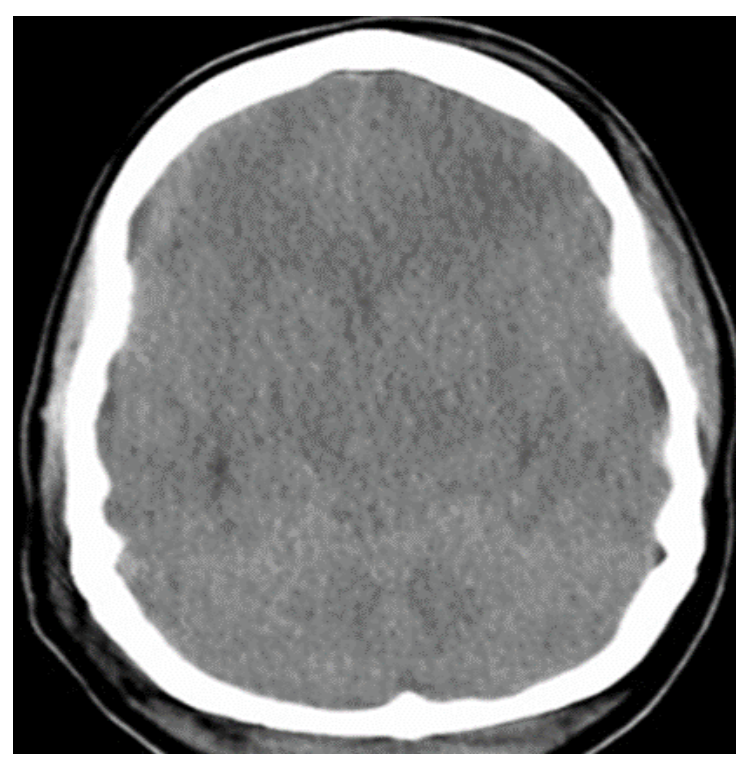

A

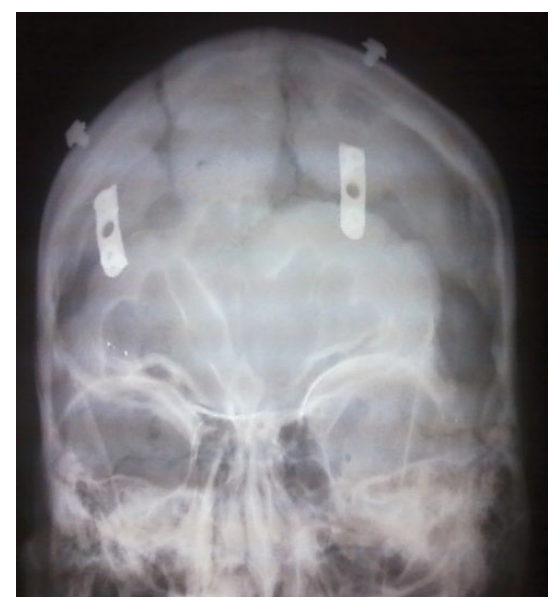

C

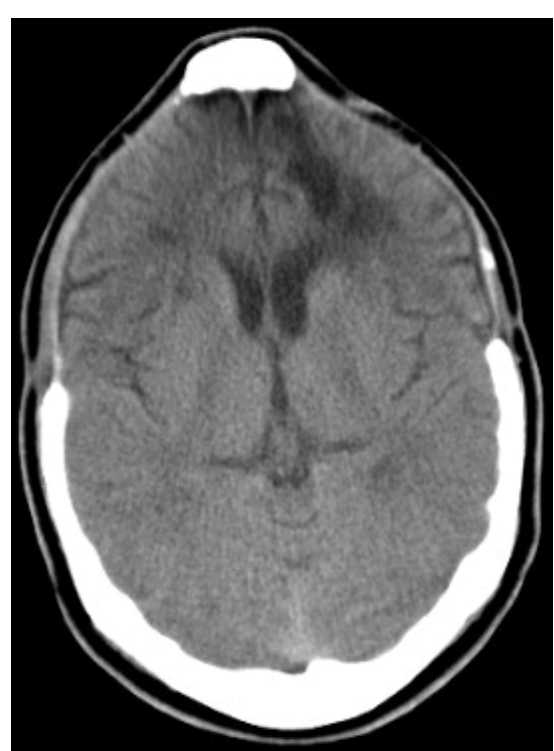

B
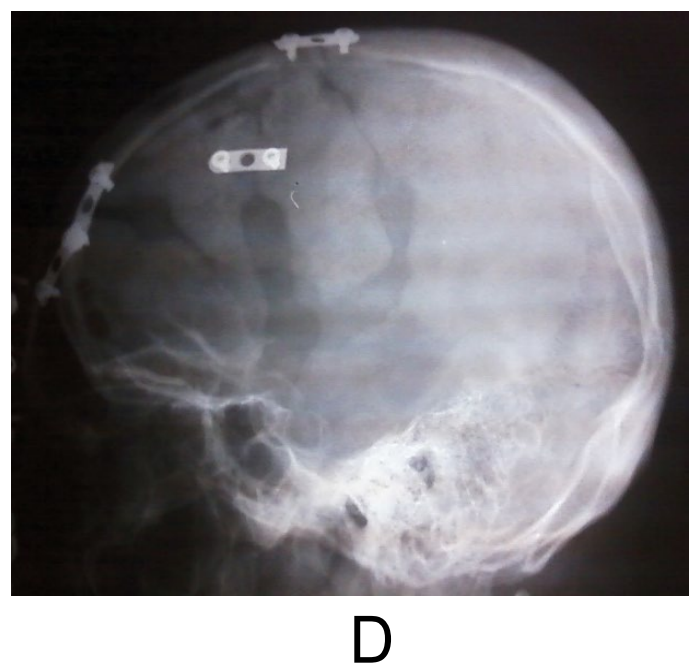

Figure 1: CT scan sequence images of a patient with bifrontal DC. a) Pre-surgical image; b) Post-surgical image; c) and d) CT scan after cranioplasty.

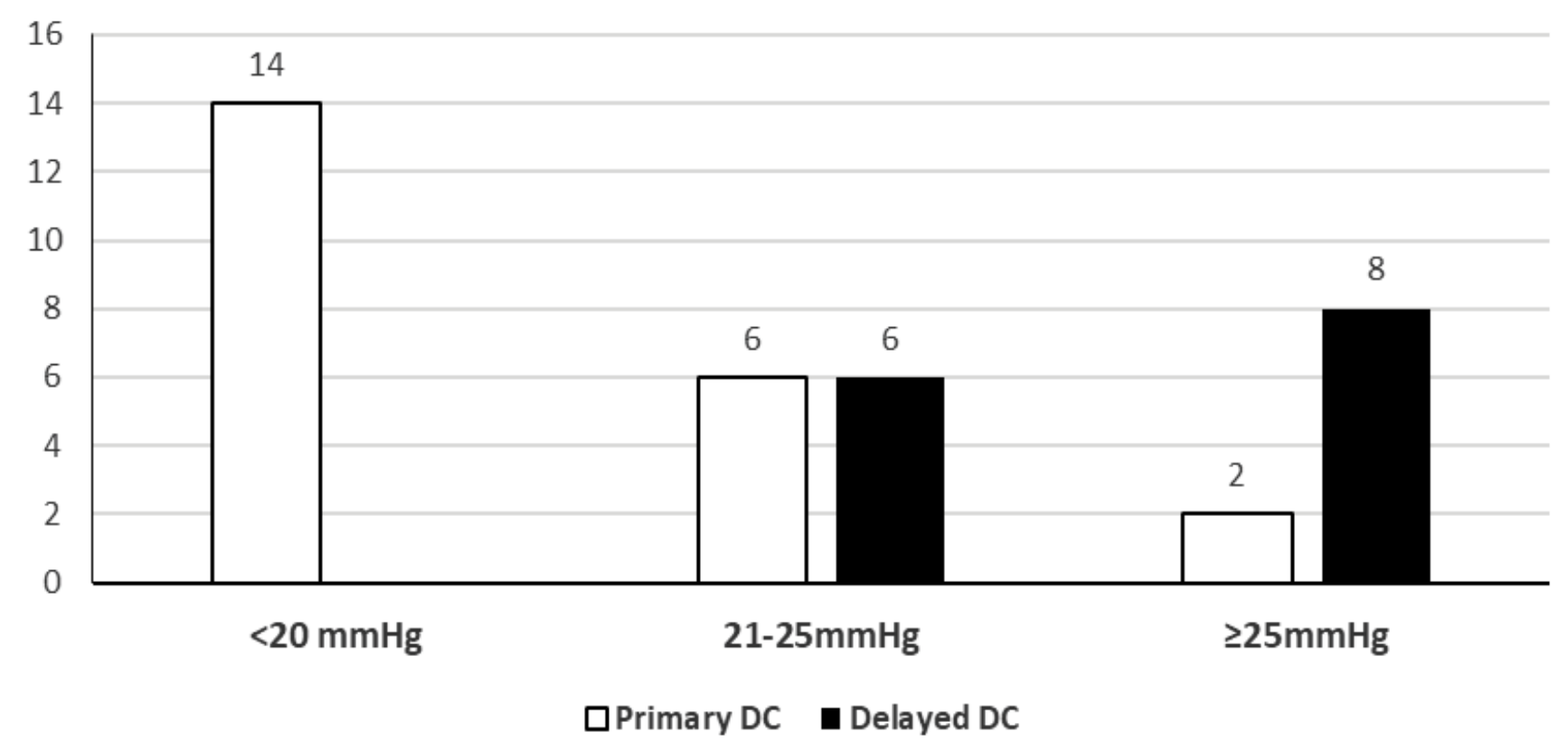

Figure 2: Relation between the moment of DC and behavior of ICP. 


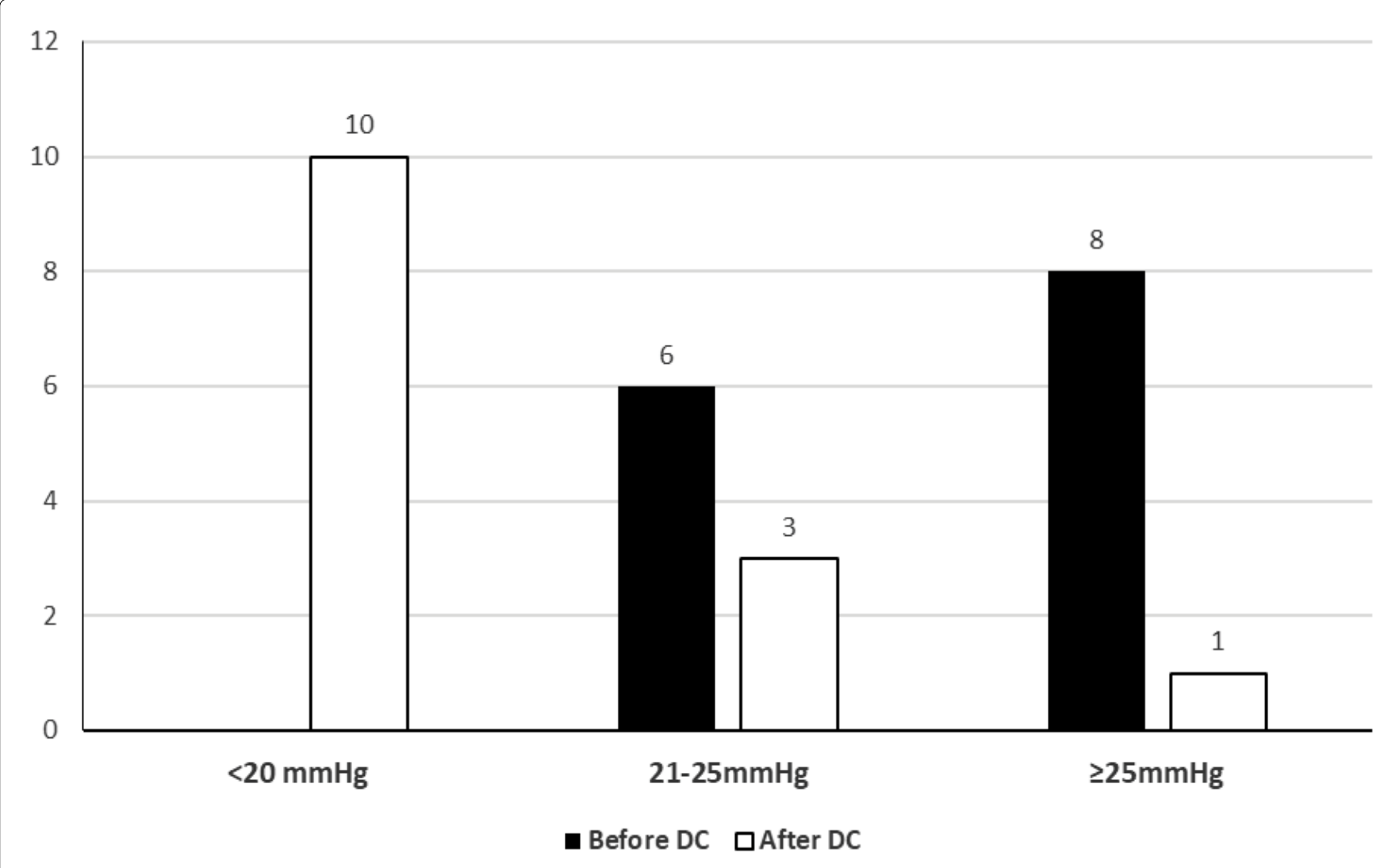

Figure 2a: Behavior of ICP in delayed DC.

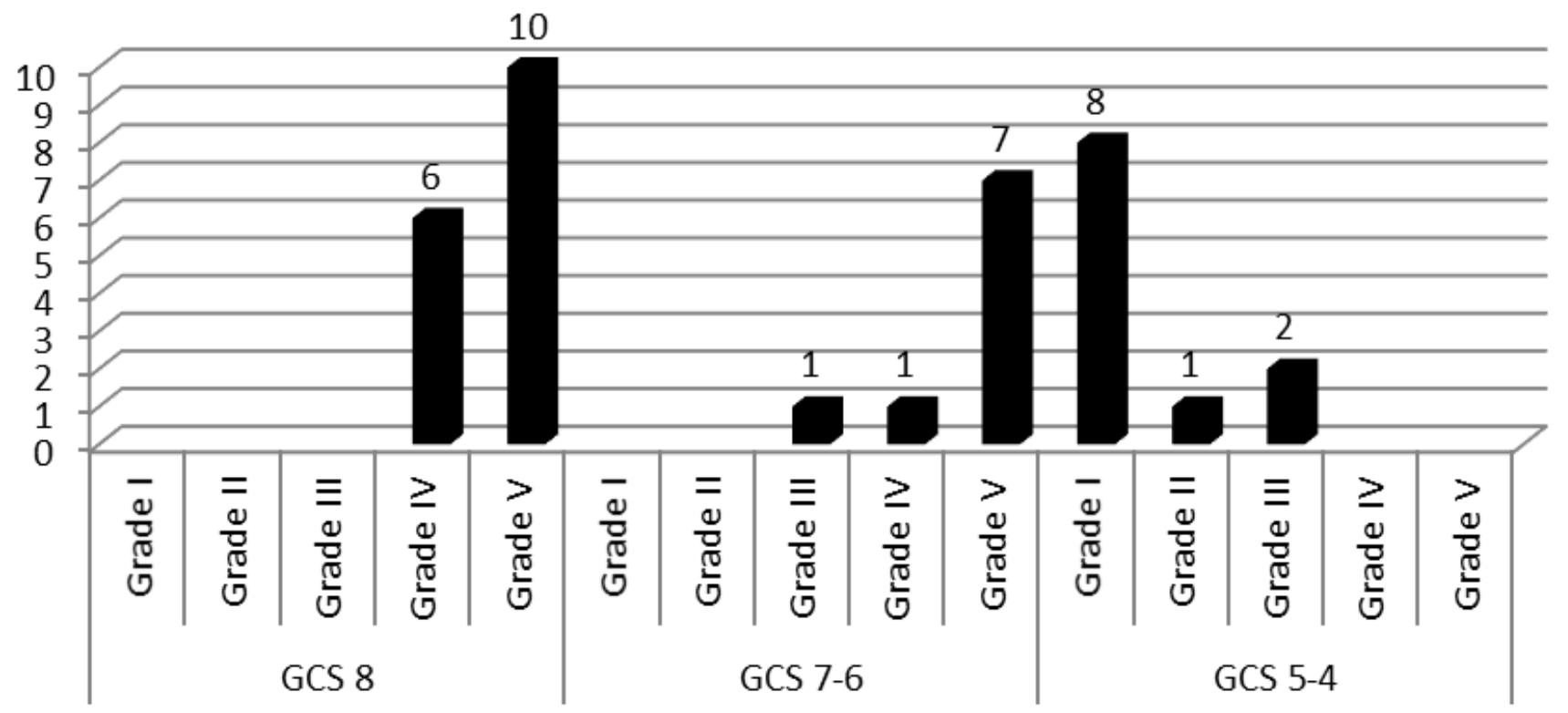

Figure 3: Relationship between GCS on admission and GCO.

Sequential CT scan images showed improvement in $24(66.67 \%)(p \leq 0.00)$, remained the same in six (16.67\%) and worsened in six (16.67\%).

The complications were divided into neurological and extra neurological, with predominance of the second. Respiratory infection was present in all cases (100\%), respiratory distress was present in six (16.67\%), hypovolemic shock in six (16.67\%) and one case $(2.77 \%)$ presented severe coagulopathy. Among the neurological complications, refractory $\mathrm{ICH}$ predominated in six cases
(16.67\%), four had hydrocephalus (11.11\%), one (2.77\%), had an external cerebrospinal fluid (CSF) fistulae and one $(2.77 \%)$ suffered from post-traumatic epilepsy.

By relating the GCS on admission and the results according to GOS, we found that 16 patients (100\%), with GCS of eight points, survived with IV and V GOS, of the nine who had GCS of 7-6 points, seven (77.78\%) remained with slight sequelae or without sequelae, one $(11.11 \%)$ with moderate sequelae and one with severe sequelae (11.11\%). Of 11 cases that on admission 
presented with GCS of 5-4 points, eight died (72.72\%) ( $p \leq 0.00$ ), one remained in a persistent vegetative state $(9.09 \%)$ and two were left with severe sequelae (18.18\%), (Figure 3).

Relation between the moment of DC and GOS is showed in Figure 4.

When observing the results at one year of evolution according to the GCS, the predominance of patients with slight sequelae or without sequelae was significant, 17
(47.22\%) and with moderate sequelae 7 (19.44\%), both groups represent a high number of patients in the series, 24 (66.67\%) ( $p \leq 0.04)$.

When stratifying the results into satisfactory and unsatisfactory, there was a predominance of the first with 26 cases $(72.22 \%)$ ( $p \leq 0.00)$ (Figure 5$)$.

\section{Discussion}

When considering ICP as the main predictor of out-

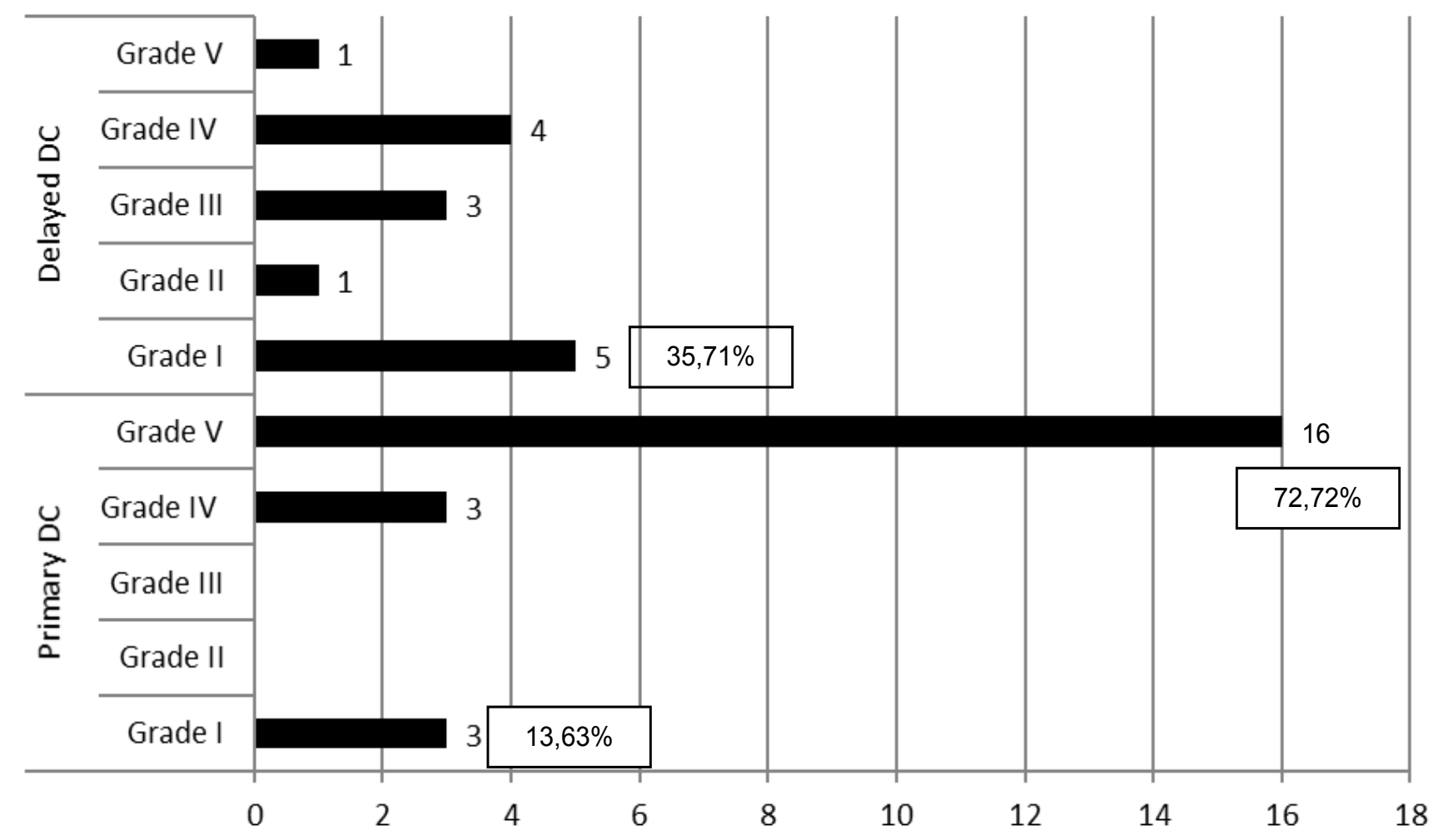

Figure 4: Relationship between the time of DC and GOS.

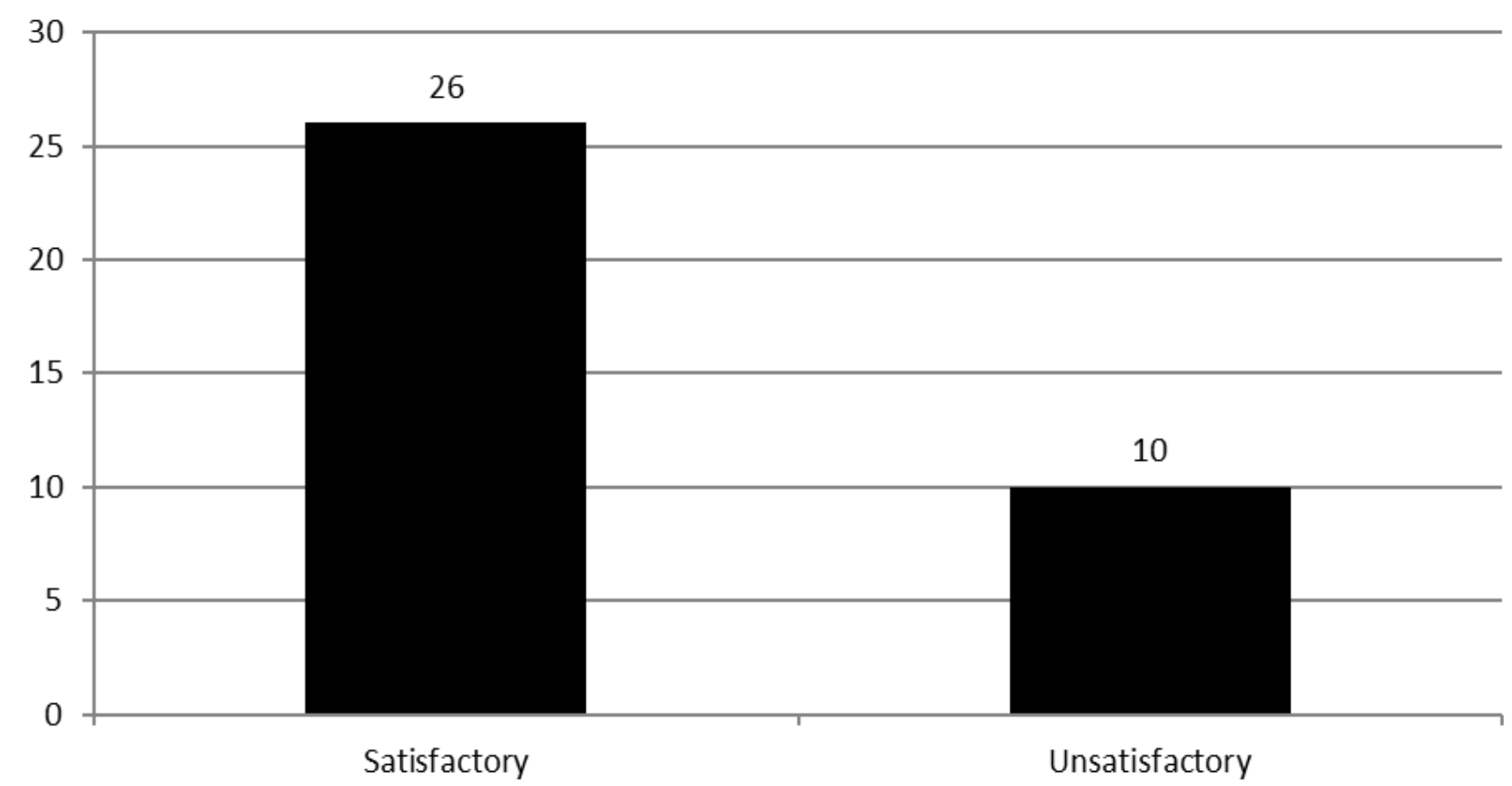

Figure 5: Stratified outcome. 
comes after severe TBI, in the last decade some authors have reported the use of $D C$ to treat refractory $I C H$ in children [8-14,18].

Although the available information on the subject is extremely scarce if we compare it with that existing in adults and if we consider that this is a surgical procedure that is generally used with the aim of controlling $\mathrm{ICH}$ refractory to the best medical treatment, then we can say that the results in many of these studies are very interesting [10-12].

Other works that have involved children only or children and adults simultaneously, with severe TBI and who have been subjected to a DC due to the existence of refractory $\mathrm{ICH}$, have reported favorable results with the procedure [19-26]. The main complications mentioned are hydrocephalus, epilepsy and cerebrospinal fluid fistula [24], which is close to the results reported in the present study.

In general, there has been a tendency to reduce the surgical window time in patients with refractory $\mathrm{ICH}$ [22], this is due to the fact that it is a brain rescue procedure, therefore exposing the brain tissue to prolonged periods of hypoxia and ischemia related to the events of $\mathrm{ICH}$, would represent an extremely high risk for the development of secondary damage, which would produce important injuries to the brain tissue with important sequelae and worsening of the results.

The multimodal monitoring of the patients allowed us to identify those who presented transient or permanent elevations of ICP and who needed to progress in the stepped treatment for $\mathrm{ICH}$, according to the established recommendations $[14,27]$, also allowed to know the behavior of the CPP and other variables such as the pressure-volume index among others, considered as a whole by the determining authors to decide the appropriate medical behavior in each case, in addition to the need to propose a surgical procedure in the patients that require it, which agrees with what was proposed by other authors [27-31].

In this study, an important influence of DC on the behavior of the ICP was found. In $63.63 \%$ of the patients who underwent a primary DC, it was possible to control the ICP below $20 \mathrm{mmHg}$, however in the group of cases in which this procedure was delayed, at 12 hours of evolution $100 \%$ showed high values of ICP before performing decompression. After the procedure was performed, the direct effect on brain compliance was verified and the ICP was controlled below $20 \mathrm{mmHg}$ in $71.43 \%$ of the cases. These results demonstrate the effect of DC on the behavior of ICP, which is not necessarily directly related to the definitive results in patients with severe TBI.

In this series, all the patients presented at the time of DC the imaging signs of intracranial hypertension, in the group in which the primary DC was performed; the images defined the surgical decision at the beginning of the treatment for the ICH. In the group of delayed DC it was found with the continuous monitoring of the ICP and its deteriorated neurological status, led to the decision to perform surgery because of the imminent risk of death.

In this context, the so-called infantile concussion syndrome [32] is framed, which is frequent in children under seven years of age, but which is usually not accompanied by imaging evidence (dislocation of midline structures) or clinical evidence (by continuous monitoring of the ICP) of ICH, so that the appearance of any of these signs persistently despite the best medical treatment, rule out this diagnostic possibility and the patient should be managed like a patient with severe TBI with refractory $\mathrm{ICH}$.

In the present study we have found difference in GOS between primary DC and delayed DC. The reduction in the mortality rate in patients with primary DC was of $22.08 \%$ in relation with those who received delayed DC and the quality of life was better too in the group of patients with primary DC.

Although the design of the present study is insufficient to reach definitive conclusions regarding the role of $D C$ in pediatric severe $T B I$, the authors consider that the neurological status of the patient and the behavior of the ICP are the parameters with the greatest influence on the results and that early DC represents an important means for the control of refractory $\mathrm{ICH}$, which is associated with satisfactory results in a group of patients that shows a high risk of mortality in our environment.

\section{References}

1. Vavilala MS, Kernic MA, Wang J, Kannan N, Mink RB, et al. (2014) Acute Care Clinical Indicators Associated with Discharge Outcomes in Children with Severe Traumatic Brain Injury. Crit Care Med 42: 2258-2266.

2. Tepas JJ, DiScala C, Ramenofsky ML (1990) Mortality and head injury: The pediatric perspective. J Pediatr Surg 25: 92-96.

3. Bell MJ, Adelson PD, Hutchison JS, Kochanek PM, Tasker RC, et al. (2013) Differences in medical therapy goals for children with severe traumatic brain injury-an international study. Pediatr Crit Care Med 14: 811-818.

4. Abreu Perez D, Lacerda Gallardo AJ, Montero Alvarez L, Martin Pardo JC (2010) Neuromonitorización y manejo del traumatismo craneoencefalico grave en pediatria. Rev Cub Med Int Emerg 9: 1830-1841.

5. Morrissey K, Fairbrother H (2016) Severe Traumatic Brain Injury in Children: An Evidence-Based Review of Emergency Department Management. Pediatr Emerg Med Pract 13: 1-28.

6. Sheriff FG, Hinson HE (2015) Pathophysiology and clinical management of moderate and severe traumatic brain injury in the ICU. Semin Neurol 35: 42-49.

7. Hutchinson PJ, Jalloh I, Helmy A, Carpenter KL, Rostami E, et al. (2015) Consensus statement from the 2014 international microdialysis forum. Intensive Care Med 41: 15171528. 
8. Young AMH, Kolias AG, Hutchinson PJ (2017) Decompressive craniectomy for traumatic intracranial hypertension: application in children. Childs Nerv Syst 33: 1745-1750.

9. Cambra FJ, Palomeque A, Munoz-Santanach D, Segura Matute S, Navarro Balbuena R, et al. (2010) Use of decompressive craniectomy in the management of refractory intracranial hypertension in paediatric patients. An Pediatr (Barc) 73: 12-18.

10. Cho DY, Wang YC, Chi CS (1995) Decompressive craniotomy for acute shaken/impact syndrome. Pediatr Neurosurg 23: 192-198.

11. Polin RS, Shaffrey ME, Bogaev CA (1997) Decompressive bifrontal craniectomy in the treatment of severe refractory posttraumatic cerebral edema. Neurosurgery 41: 84-94.

12. Taylor A, Warwick B, Rosenfeld J (2001) A randomized trial of very early decompressive craniectomy in children with traumatic brain injury and sustained intracranial hypertension. Childs Nerv Syst 17: 154-162.

13. Oluigbo CO, Wilkinson CC, Stence NV, Fenton LZ, McNatt SA, et al. (2012) Comparison of outcomes following decompressive craniectomy in children with accidental and nonaccidental blunt cranial trauma. J Neurosurg Pediatr 9: 125-132.

14. Kochanek PM, Carney N, Adelson PD, Ashwal S, Bell MJ, et al. (2012) Guidelines for the acute medical management of severe traumatic brain injury in infants, children, and adolescents-second edition. Pediatr Crit Care Med 13: S1S82.

15. Teasdale G, Jennett B (1974) Assesment of coma and impaired onsciousness. A practical scale. Lancet 13: 81-84.

16. Marshall LF, Gautille T, klauber MR, Eisenberg HM, Jane JA, et al. (1991) The outcome of severe closed head injury. J Neurosurg 75: 528-536.

17. Beers SR, Wisniewski SR, Garcia-Filion P, Tian Y, Hahner T, et al. (2012) Validity of a Pediatric Version of the Glasgow Outcome Scale-Extended. J Neurotrauma 29: 1126-1139.

18. Lacerda Gallardo AJ, Abreu Perez D, Diaz Agramonte JA Perez Leal S, Martin Pardo JC, et al. (2013) Craniectomia descompresiva en el manejo del traumatismo craneoencefalico grave en pediatria. Rev Cubana Neurol Neurocir 3: 38-43.

19. Perez Suarez E, Serrano Gonzalez A, Perez Diaz C, Garcia Salido A, Martinez de Azagra Garde A, et al. (2011) Decompressive craniectomy in 14 children with severe head injury: clinical results with long-term follow-up and review of the literature. J Trauma 71: 133-140.

20. Jacob AT, Heuer GG, Grant R, Georgoff P, Danish SF, et al. (2011) Decompressive hemicraniectomy for pediatric traumatic brain injury: long-term outcome based on quality of life. Pediatr Neurosurg 47: 81-86.

21. Gilresir E, Schuss P, Seifert V, Vatter H (2012) Decompressive craniectomy in children: single-center series and systematic review. Neurosurgery 70: 881-889.

22. Csokay A, Emelifeonwu JA, Filgedi L, Valilik I, Ling J (2012) The importance of very early decompressive craniectomy as a prevention to avoid the sudden increase of intracranial pressure in children with severe traumatic brain swelling (retrospective case series). Childs Nerv Syst 28: 441-444.

23. Glick RP, Ksendzovsky A, Greesh J, Raksin P (2011) Initial observations of combination barbiturate coma and decompressive craniectomy for the management of severe pediatric traumatic brain injury. Pediatr Neurosurg 47: 152-157.

24. Adamo MA, Drazin D, Waldman JB (2009) Decompressive craniectomy and postoperative complication management in infants and toddlers with severe traumatic brain injuries. J Neurosurg Pediatr 3: 334-339.

25. Liu H, Wang W, Cheng F, Yuan Q, Yang J, et al. (2014) External ventricular Drains versus Intraparenchymal Intracranial Pressure Monitors in Traumatic Brain Injury: A Prospective Observational Study. World Neurosurg 23: 18788750.

26. Cavuayoaylu H, Kaya RA, Tarkmenoaylu ON, Aydin Y (2010) Value of early unilateral decompressive craniectomy in patients with severe traumatic brain injury. Ulus Travma Acil Cerrahi Derg 16: 119-124.

27. Hardcastle N, Benzon HA, Vavilala MS (2014) Update on the 2012 guidelines for the management of pediatric traumatic brain injury - information for the anesthesiologist. Paediatr Anaesth 24: 703-710.

28. Le Roux P (2014) Intracranial pressure after the BEST TRIP trial: a call for more monitoring. Curr Opin Crit Care 20: $141-147$.

29. Yuan Q, Wu X, Yu J, Sun Y, Li Z, et al. (2015) Effects and Clinical Characteristics of Intracranial Pressure Monitoring-Targeted Management for Subsets of Traumatic Brain Injury: An Observational Multicenter Study. Crit Care Med 23: 118-136.

30. Frontera J, Ziai W, O'Phelan K, Leroux PD, Kirkpatrick PJ, et al. (2015) Regional Brain Monitoring in the Neurocritical Care Unit. Neurocrit Care 22: 348-359.

31. Kawoos U, McCarron RM, Auker CR, Chavko M (2015) Advances in Intracranial Pressure Monitoring and Its Significance in Managing Traumatic Brain Injury. Int J Mol Sci 16: 28979-28997.

32. Duncan CHC, Ment LR, Ogle E (1989) Traumatic injury to the developing brain. En: Marlin AE. Eds. Concepts pediatric neurosurgery. Ciudad: Basel-Karger 211-229. 